\title{
Pelvic Multifocal Primitive Bone Epithelioid Angiosarcoma (Iliac Crest and Hip) about One Case and Literature Review
}

\section{Samba Koné ${ }^{*}$, Abidou Coulibaly², Nawe Astride Ngandeu², Kouadio J. N'dah ${ }^{3}$, Stanislas Touré1, Adoulaye Bana ${ }^{1}$, Serge Agoh', N'zué Kouakou ${ }^{2}$}

${ }^{1}$ Traumatology Orthopaedics' Ward Cocody's UHC, Abidjan, Ivory Coast

${ }^{2}$ Rheumatology Ward Cocody's UHC, Abidjan, Ivory Coast

${ }^{3}$ Anatomo-Pathologyward Cocody's UHC, Abidjan, Ivory Coast

Email: *k.samba06@gmail.com

How to cite this paper: Koné, S., Coulibaly, A., Ngandeu, N.A., N'dah, K.J., Touré, S., Bana, A., Agoh, S. and Kouakou, N. (2017) Pelvic Multifocal Primitive Bone Epithelioid Angiosarcoma (Iliac Crest and Hip) about One Case and Literature Review. Open Journal of Pathology, 7, 58-65. https://doi.org/10.4236/ojpathology.2017.7 $\underline{3006}$

Received: May 29, 2017

Accepted: July 19, 2017

Published: July 24, 2017

Copyright $\odot 2017$ by authors and Scientific Research Publishing Inc. This work is licensed under the Creative Commons Attribution International License (CC BY 4.0).

http://creativecommons.org/licenses/by/4.0/

\begin{abstract}
Epithelioid angiosarcoma is a rare vascular tumour with dark prognosis at short term. The primitive bone localization is exceptional and sometimes presents itself under a unifocal form. We report a clinical case of pelvic multifocal primitive bone epithelioid angiosarcoma (iliac crest and hip) diagnosed on a young male adult ( 45 years old). The radiological investigations put in evidence geographic osteolytic lesions (type IC) and, diagnostic was given thanks to the histological examination of the surgical biopsy pieces. The evolution was marked by the appearance of pulmonary and lymph node metastases with a death occurring in less than 4 months. Extremely rare tumour, bone epithelioid angiosarcoma is a variant of angiosarcoma characterised by an aggressive nature whose evolution is always fatal. Through this observation we report our experience on the diagnostic approach; and using a literature review we discuss the therapeutic modalities of this tumour with very bad prognosis.
\end{abstract}

\section{Keywords}

Epithelioid Angiosarcoma, Bone, Primitive, Multifocal

\section{Introduction}

Epithelioid angiosarcoma is a rare vascular tumour (1\% of soft tissues sarcomas) [1] [2]. Most of these tumours are primitive [3]. It is sometimes described at the level of soft tissues (liver, lung), and can affect the osseous tissue. The bone localization sometimes described has a metastatic origin; bone primitive damage is exceptional. It is a highly malignant tumor whose symptoms are not specific but 
the pain dominates the clinical picture, followed by the appearance of a swelling and a rapid clinical evolution. The radiological aspect is the most frequent, that it is a lytic image, poorly limited with extension in the adjacent soft tissues. The most frequent radiological aspect is a lytic image, poorly limited with extension in the adjacent soft tissues.

CT scan and MRI complete the standard radiography, specifying the tumor's bone limits, in particular the cortical damage, as well as the invasion of the surrounding soft tissues.

The diagnostic is essentially histological and or immunohistochemical.

At the histological plane, the angiosarcoma is characterised by a high degree of anaplasia. The malignant bone hemangioendothelioma is composed of anastomosing vascular ducts lined with atypical endothelial cells with enlarged nuclei, prominent nucleoli and increased mitoses. Inflammatory (eosinophilic) cells may be present.

However, the histological diagnosis is not free of difficulties because of the similarity with other bone tumors (primitive vascular or osteophytic cancer metastasis).

The complete surgical resection (treatment of choice) has to be coupled to radiotherapy. Occasionally, adjuvant chemotherapy is decided but has not proven to be effective.

Epithelioid angiosarcoma has a very high malignant potential [3] [4], so with an aggressive evolution with most of the time metastases. The sites of choice for metastasis are bone, lung and lymph nodes.

The prognosis is dark at short term.

We report a clinical case of pelvic multifocal primitive bone epithelioid angiosarcoma (iliac crest and hip) diagnosed on a young male adult.

\section{Case Report}

Mr. A. T., 45 years old, admitted in the rheumatology ward for a left low back pain and alteration of the general body state. The disease history reveals a beginning started 8 months before his admission, by the appearance of a left mechanic low back pain, without irradiation, calmed by the usual analgesics. Progressively, this pain took a permanent inflammatory character with an increase in intensity and an extension to the ipsilateral hip, creating a mobility limitation. An absolute functional impotence appeared after a fall of its height.

The physical examination found a major general body state alteration, a pain at 9 on 10 on the visual analog pain scale. On the left hip, we noticed a hip vicious attitudein flexum, a greater tronchanteric pain with an impossible hip mobilisation. The Larrey and Verneuil maneuver was positive. There were no other extra articular signs. The other apparatus looked without any particularities.

The past medical history noticed a tuberculosis contact 4 years before the signs beginning. There was no notion of particular exposition or irradiation.

The radiological report shows a type IC Lodwick [5] osteolytic lesion at the level of the femoral neck (Figure 1) and the iliac wings and cortical rupture (Figure 2). 

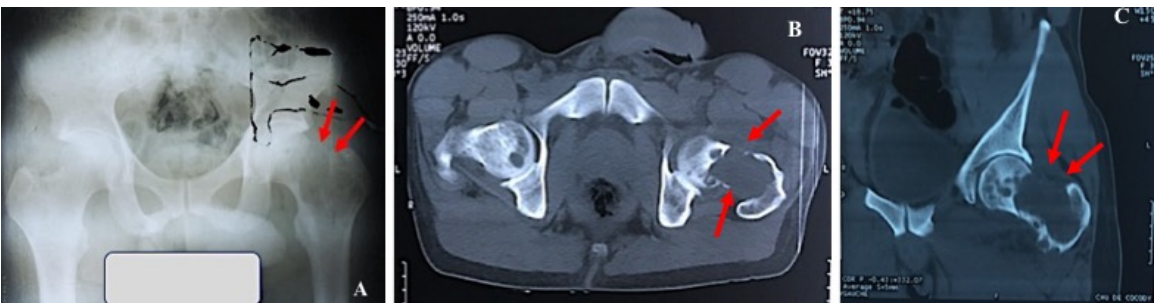

Figure 1. Pelvis X-ray (A) antero-posterior; Pelvis CT scan; (B) sagittal; (C) coronal showing: osteolytic lesion at the level of the femoral neck (arrow in yellow) and the iliac wings (arrow in red).

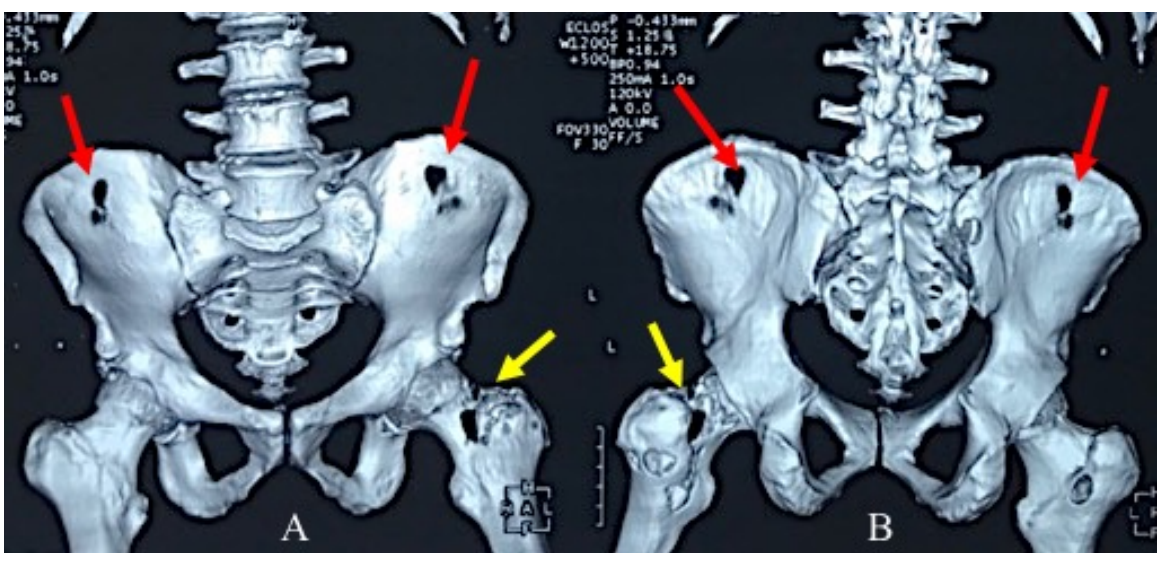

Figure 2. Pelvis CT scan, reconstruction (A) a front view; (B) a view from below showing: osteolytic lesion at the level of the femoral neck (arrow in yellow) and the iliac wings (arrow in red).

The biological report was resumed as a discrete inflammatory syndrome (SR: $34 \mathrm{~mm}$ at the first hour, CRP: $96 \mathrm{mg} / \mathrm{L}$ ); a microcytic anaemia; a polyclonal hypergammaglobulinemia and a marrow very rich in proliferative cytological elements (myelogram).

A radiologic exploration (thoracic and abdomino-pelvic TDM, gastrointestinal endoscopy) to research a metastatic carcinoma or another localization was negative. The tumour markers (alpha-fetoprotein, carcino-embyonic antigen, prostatic specific antigen) were normal.

A surgical biopsy was performed after an anterior approach of the hip and provisional filling by a spacer. Pathologic examination suggests the diagnosis of grade 3 epithelioid angiosarcoma of the FNCLCCL (Figure 3) [6].

A multidisciplinary consultation (surgeon, rheumatologist, oncologist, and histopathologist) to make a choice of indication and therapeutic protocol was conducted. Unfortunately patient died of the disease 4 months after diagnosis in a major alteration of general body condition with pulmonary and ganglionic metastases.

\section{Discussion}

The primitive bone angiosarcoma is a rare tumour representing less than $1 \%$ of primitive malignant bone tumours (PMBT) [1] [2]. Epithelioid angiosarcoma is 

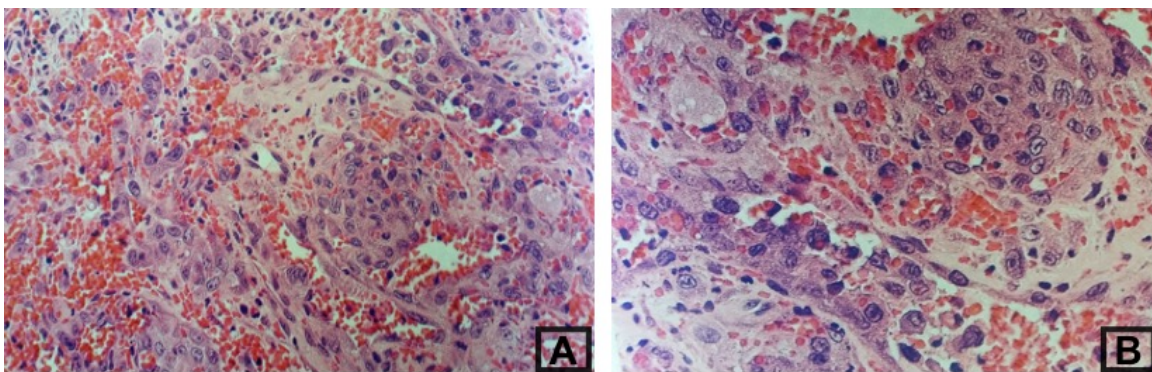

Figure 3. Microscopic appearance of epithelioid angiosarcoma on different magnifycations showing: (A) (HEx25) Angiomatous proliferation made by vascular clefts filled with atypical epithelioid cells (anisocaryosis and mitoses); (B) (HEx40) Mass of atypical ovoid or round cells (cytoplasm sometimes vacuolated with vesicular and nucleolus nuclei).

an angiosarcoma variant, characterized by a bad differentiation and biological aggressiveness. The primitive bone localization is exceptional. These tumours can occur in different part of the bone, but the predilection site is long bone extremities [1]-[8]. Other sites have been reported: pelvis [9], and spine [4]. In our case it was a multifocal damage of the pelvis (iliac crest) and the femur neck.

Our patient age was 45 years whereas the median age of bone angiosarcoma reported in the literature varies between 60 up to 71 years [7] [8]. Men incidence is slightly higher than that of women [3] [9].

Patients may have a unifocal or multifocal bone lesion [3] [10] as was the case in our patient.

Bone metastatic cancer's biological markers negativityconfirms the primitive pelvic origin. In case of multifocal lesions, the difficulty is to know if this last is synchronous in a multiple form or the result of metastases [11]. Apart from these primary forms, secondary angiosarcoma has been reported in patients with overweight status [12], following prosthetic implant [13], or irradiation (radiotherapy) [14]. On our patient, no risk factor has been identified.

Many authors precise that the angiosarcoma radiological signs are not specific [3] [9] [15]. They are summarized in a geographic osteolysis with blurred limit of type IC [5] which because of its aggressiveness and its rapidity of extension no periosteal reaction does have time to settle. The tomodensitometry is effective to evaluate tumour limits, bone lyses, calcification matrix and periosteal appositions. The magnetic resonance imaging (MRI) is fundamental to evaluate the locoregional extension (osseous, soft tissues, vascular structures, skip metastasis).

This osteolysis usually involves bone metastatic carcinomas (osteophytic cancer) or PMBT (Chondrosarcoma, osteosarcoma, Ewing's sarcoma, leiomyosarcoma); and less often primary osseous vascular tumours.

The diagnosis of epithelioid angiosarcoma is exclusively anatomopathological, which must be carried out by an anatomopathologist experienced in oncology.

On the histological plan, interpretation is not free from difficulties [11] [16] [17].

Indeed, bone metastatic carcinoma can be difficult to distinguish from epithelioid angiosarcoma because it is also composed of epithelioid type tumour cells [17] [18]. 
On the other hand, it is necessary to eliminate epithelial-like tumours (haemangioma, epithelioid haemangioma or epithelioid hemangio-endothelioma) due to histological similarities with epithelioid angiosarcoma [18].

The certitude diagnostic is provided by histological examination of the biopsy pieces.

Nowadays, thanks to immunohistochemical marking processes, we can separate a primitive tumour of the bone and a bone metastasis; and alsodifferentiate the primary vascular tumours of bone.

The vascular tumours variably express the endothelial markers, some of which have membrane expression (CD-31 and CD34, MMA), cytoplasmic expression (von Willebrand factor and factor VIII), nuclear expression (Interleukine-1 factor (ILF-1)) or epithelial expression, (cytokeratin and MMA). (Table 1) [8] [18] [19]. The CD31 and ILF-1 are sensitive and specific to blood vessels [9] [15] [19].

We did not have immunohistochemistry, we made the diagnosis on the basis of clusters arguments. The clinical and biologicalarguments were: alteration of the general state, absence of primary osteophylic cancer site, negativity of biological markers for primary cancer. The radiological arguments were based on osteolysis with blurred limit, cortical rupture, calcification or partition absence. On the histological plan there were epithelioid cells bordering the cavities, cytonuclear atypia, with a high mitotic index, and sometimes cytoplasmic vacuoles which contain red blood cells.

The therapeutic management of PMBT seems well codified. Treatment of bone angiosarcoma typically involves a carcinological surgery (monoblock excision) in combination with radiotherapy and or chemotherapy [20].

Surgically it consists in a complete surgical resection associated with various complex reconstruction procedures. All are unanimous that it is a difficult, heavy, hemorrhagic surgery, which requires a team used to practice. Radiotherapy is proposed in adjuvant method and allows a local and late control with good functional and cosmetic results [3] [21] [22] at short term because the prognosis of this tumour is dark. Neo adjuvant chemotherapy indicated in multifocal lesions or metastasis has not yet proved its efficacy on overall survival.

Table 1. Immunohistochemical expression of markers depending on the type of tumor (+ positive, - negative).

\begin{tabular}{ccccc}
\hline & Angiosarcoma & EHE & other sarcoma & Carcinoma \\
\hline Cytokératin & $+/-$ & $+/-$ & $+/-$ & + \\
MMA & $+/-$ & $+/-$ & $+/-$ & + \\
CD31 & + & + & - & - \\
CD34 & + & + & $+/-$ & - \\
Factor VIII & $+/-$ & $+/-$ & - & - \\
ILF-1 & + & + & - & - \\
\hline
\end{tabular}


However a hope appears through the significant results obtained with doxorubicin, and paclitaxel, weekly [3] [23].With its aggressive evolution the survival rate at 5 years is around $10 \%$ to $30 \%$. In case of metastasis this rate is around 8 months [13]. Our patient died 4 months later, with metastases (pulmonary and ganglionic), which testifies the rapid and aggressive evolution of this tumour entity.

\section{Conclusions}

Primary epithelioid angiosarcoma of the bone is extremely rare.

Osteolytic tumour is often multifocal, and can pose a histological diagnosis problem and therapeutic difficulties. It is all the interest of a multidisciplinary consultation.

Its very high malignancy potential, aggressive nature combined with its metastatic power augurs a dark prognosis at short-term.

\section{Consent}

The patient and the families were informed that data from the case would be submitted for publication and provided their consent accordingly.

\section{Conflict of Interests}

The authors declare that they have no competing interests.

\section{Author's Contributions}

All the authors contributed of the writing of this manuscript andhaveread and approved the final version.

\section{References}

[1] Deshpande, V., Rosenberg, A.E., O'connell, J.X. and Nielsen, G.P. (2003) Epithelioid Angiosarcoma of the Bone: A Series of 10 Cases. The American Journal of Surgical pathology, 27, 709-716. https://doi.org/10.1097/00000478-200306000-00001

[2] Abraham, J.A., Hornicek, F.J., Kaufman, A., et al. (2007) Treatment and Outcome of 82 Patients with Angiosarcoma. Annals of Surgical Oncology, 14, 1953-1967. https://doi.org/10.1245/s10434-006-9335-y

[3] Brouchet, A., Moretti, A., Penel N., et al. (2012) Tumeurs Vasculaires Primitives Osseuses. EMC Appareil Locomoteur, 7, 4.

[4] Lang, J., Chen, L., Chen, B., Chen, K., et al. (2014) Epithelioid Angiosarcoma of the Spine: A Case Report of a Rare Bone Tumor. Oncology Letters, 7, 2170-2174. https://doi.org/10.3892/ol.2014.2055

[5] Lodwick, G.S., Turner, A.H., Lusted, L.B. and Templeton, A.W. (1966) Computer-Aided Analysis of Radiographic Images. Journal of Chronic Diseases, 19 485IN1487-486IN2496. https://doi.org/10.1016/0021-9681(66)90122-6

[6] Guillou, L., Coindre, J.M., Bonichon, F., et al. (1997) A Comparative Study of the NCI and FNCLCC Grading Systems in a Population of 410 Adult Patients with a Soft Tissue Sarcoma. Journal of Clinical Oncology, 15, 350-362. https://doi.org/10.1200/JCO.1997.15.1.350 
[7] Sakamoto, A., et al. (2014) Aggressive Clinical Course of Epithelioid Angiosarcoma in the Femur: A Case Report. Word Journal of Surgical Oncology, 12, 281. https://doi.org/10.1186/1477-7819-12-281

[8] Verbeke, S.L., Bertoni, F., Bacchini, P., Sciot, R., et al. (2011) Distinct Histological Features Characterize Primary Angiosarcoma of Bone. Histopathology, 58, 254-264. https://doi.org/10.1111/j.1365-2559.2011.03750.x

[9] Chen, M.X., Zhang, W., Qu, J.L., et al. (2014) Epithelioid Angiosarcoma of the Ilium: A Case Report. International Journal of Clinical and Experimental Pathology, 7, 9099-9103

[10] Mitsuhashi, T., Shimizu, Y., Ban, S., Ogawa, F., et al. (2005) Multicentric Contiguous Variant of Epithelioid Angiosarcoma of the Bone: A Rare Variant Showing Angiotropic Spread. Annals of diagnostic pathology, 9, 33-37. https://doi.org/10.1053/j.anndiagpath.2004.10.005

[11] Santeusanio, G., Bombonati, A., Tarantino, U., et al. (2003) Multifocal Epithelioid Angiosarcoma of Bone: A Potential Pitfall in the Differential Diagnosis with Metastatic Carcinoma. Applied Immunohistochemistry \& Molecular Morphology, 11, 359-363. https://doi.org/10.1097/00129039-200312000-00014

[12] Zver, S., Bracko, M. and Andoljsek, D. (2010) Primary Bone Angiosarcoma in a Patient with Gaucher Disease. International Journal of Hematology, 92, 374-377. https://doi.org/10.1007/s12185-010-0643-4

[13] Drexler, M., Dolkart, O., Amar, E., Pritsch, T. and Dekel, S. (2010) Late Recurrent Hemarthrosis Following Knee Arthroplasty Associated with Epithelioid Angiosarcoma of Bone. The Knee, 17, 365-367. https://doi.org/10.1016/j.knee.2009.10.010

[14] Mittal, S., Goswami, C., Kanoria, N. and Bhattacharya, A. (2007) Post-Irradiation Angiosarcoma of Bone. Journal of Cancer Research and Therapeutics, 3, 96. https://doi.org/10.4103/0973-1482.34687

[15] Yang, Z., Tao, H., Ye, Z. and Yang, D. (2012) Multicentric Epithelioid Angiosarcoma of Bone. Orthopedics, 35, 1293-1296. https://doi.org/10.3928/01477447-20120725-39

[16] Baliaka, A., Balis, G., Michalopoulou-Manolout-Siou, E., et al. (2013) Primary Angiosarcoma of Bone. A Case Report. Hippokratia, 17, 180-182.

[17] Hart, J. and Mandavilli, S. (2011) Epithelioid Angiosarcoma: A Brief Diagnostic Review and Differential Diagnosis. Archives of Pathology \& Laboratory Medicine, 135, 268-272.

[18] Gill, R., O’Donnell, R.J. and Horvai, A. (2009) Utility of Immunohistochemistry for Endothelial Markers in Distinguishing Epithelioid Hemangioendothelioma from Carcinoma Metastatic to Bone. Archives of Pathology \& Laboratory Medicine, 133, 967-972.

[19] Chen, Y., Shen, D., Sun, K., Bao, D., et al. (2011) Epithelioid Angiosarcoma of Bone and Soft Tissue: A Report of Seven Cases with Emphasis on Morphologic Diversity, Immunohistochemical Features and Clinical Outcome. Tumori, 97, 585-589.

[20] Palmerini, E., Maki, R.G., Staals, E.L., Alberghini, M., et al. (2014) Primary Angiosarcoma of Bone: A Retrospective Analysis of 60 Patients from Two Institutions. American Journal of Clinical Oncology, 37, 528. https://doi.org/10.1097/COC.0b013e31827defa1

[21] Lewis, C.J., Gerrand, C., Barnes, D.E., Murray, S., et al. (2011) Experience of Angiosarcoma in the North of England Bone and Soft Tissue Tumour Service. Journal of Plastic, Reconstructive \& Aesthetic Surgery, 64, 884-891. 
https://doi.org/10.1016/j.bjps.2010.11.016

[22] Sasaki, R., Soejima, T., Kishi, K., Imajo, Y., et al. (2002) Angiosarcoma Treated with Radiotherapy: Impact of Tumor Type and Size on Outcome. International Journal of Radiation Oncology Biology Physics, 52, 1032-1040. https://doi.org/10.1016/S0360-3016(01)02753-5

[23] Penel, N., Italiano, A., Ray-Coquard, I., Chaigneau, L., et al. (2012) Metastatic Angiosarcomas: Doxorubicin-Based Regimens, Weekly Paclitaxel and Metastasectomy Significantly Improve the Outcome. Annals of Oncology, 23, 517-523.

https://doi.org/10.1093/annonc/mdr138

\section{Abbreviation}

FNCLCCL: FrenchFédération Nationale des Centres de Lutte Contre le Cancer

CD: Cluster of differentiation

MMA: Mouse Monoclonal Antibody

EHE: epithelioid hemangio-endothelioma

ILF-1: interleukin factor

PMBT: Primitive malignant bone tumour

MRI: magnetic resonance imaging

\section{Scientific Research Publishing}

Submit or recommend next manuscript to SCIRP and we will provide best service for you:

Accepting pre-submission inquiries through Email, Facebook, LinkedIn, Twitter, etc. A wide selection of journals (inclusive of 9 subjects, more than 200 journals)

Providing 24-hour high-quality service

User-friendly online submission system

Fair and swift peer-review system

Efficient typesetting and proofreading procedure

Display of the result of downloads and visits, as well as the number of cited articles

Maximum dissemination of your research work

Submit your manuscript at: http://papersubmission.scirp.org/

Or contact ojpathology@scirp.org 